\title{
Disordered eating attitudes: demographic and clinico-anthropometric correlates among a sample of Nigerian students.
}

\author{
Babatunde Fadipe ${ }^{2}$, Motunrayo Atinuke Oyelohunnu², Andrew Toyin Olagunju1,2,3, \\ Olatunji Francis Aina ${ }^{1,2}$, Abiola Adelphine Akinbode ${ }^{1}$, Tajudeen Folorunsho Suleiman ${ }^{2}$
}

1. Department of Psychiatry, College of Medicine, University of Lagos, PMB 12003, Lagos, Nigeria

2. Department of Psychiatry, Lagos University Teaching Hospital, PMB12003, Lagos, Nigeria

3. Discipline of Psychiatry, School of Medicine, University of Adelaide, Adelaide Health and Medical Sciences Building, North Terrace, Adelaide, SA 5000, Australia

\begin{abstract}
Objectives: We set out in this study to determine the demographic and clinico-anthropometric correlates of disordered eating attitudes among undergraduate students of two higher institutions in Lagos, Nigeria.

Methods: This cross-sectional descriptive study was conducted among 1,054 participants after written informed consent. A socio-demographic questionnaire, the Eating Attitude Test (EAT-26) and 12-item General Health Questionnaire (GHQ-12) were administered to the participants. In addition, their blood pressure, height and weight were measured, and body mass index (BMI) was calculated.

Results: The study participants comprised of 561(55.6\%) males with median age of 21.4 years. The mean $( \pm \mathrm{SD})$ score on EAT-26 was $11.52( \pm 8.54)$, and $16 \%$ of all the respondents were categorized as having disordered eating attitude. A significant relationship was found between disordered eating attitude and age $(p=0.027)$, gender $(p=<0.001)$, institution of study $(p=$ $0.005)$, systolic blood pressure $(\mathrm{p}=0.019), \mathrm{BMI}(\mathrm{p}=0.027)$ and psychological distress $(\mathrm{p}=0.005)$.

Conclusion: Our study observed disordered eating attitude to be prevalent among young adults, and demographic along with clinico-anthropometric factors constituted associated factors. Our findings strengthen the basis to incorporate health awareness programs aimed at improving nutrition and eating behavior among the young adult population. Future research is needed.
\end{abstract}

Keywords: Anthropometric, correlates, disordered eating attitudes, Nigeria, students.

DOI: https://dx.doi.org/10.4314/ahs.v17i2.27

Cite as: Fadipe B, Oyelobunnu MA, Olagunju AT, Aina OF, Akinbode AA, Suleiman TF. Disordered eating attitudes: demographic and clinico-anthropometric correlates among a sample of Nigerian students. Afri Health Sci. 2017;17(2): 513-523. https:/ / dx.doi.org/10.4314/ ahs.v17i2.27

\section{Introduction}

Generally, young people tend to be influenced by the perception of their body shape and size ${ }^{1-3}$. While this may be a normal part of development, morbid situations exist in which individuals have abnormal perceptions of their body image, accompanied by abnormality in their weight and eating behaviors. Such conditions are referred to as eating disorders and can result in a multitude of
Corresponding author:
Andrew Toyin Olagunju,
Department of Psychiatry,
College of medicine,
University of Lagos,
PMB 12003, Lagos, Nigeria
Phone: +2348058841643
Email: aolagunju@unilag.edu.ng
or andyolagus@yahoo.com

life-threatening conditions. According to the $10^{\text {th }}$ edition of the International Classification of Diseases (ICD10) and the $5^{\text {th }}$ edition of the Diagnostic and Statistical Manual of mental disorders (DSM-V), eating disorders include but are not limited to anorexia nervosa (AN), and bulimia nervosa $(\mathrm{BN})^{4,5}$. The above listed disorders constitute more severe clinical forms of a group of disorders that are believed to occur along a spectrum with milder variants which typically do not meet specific criteria for the more severe forms ${ }^{6,7}$. Disordered eating attitudes are abnormal beliefs, thoughts, feelings and behaviors regarding food which may occur along the continuum with eating disorders and can therefore be considered milder variants of eating disorders ${ }^{8}$. They are likely precursor or indicator to the presence of eating disorders?

The enormity of the consequences of eating disorders as well as disordered eating attitudes is such that it has been linked with increased suffering. For example, persons with 
eating disorders experience higher rates of other mental illnesses, medical/physical complications, impairments in the fulfillment of roles, suicidality, poor quality of life and overall high levels of mortality ${ }^{10-13}$. However, it is not uncommon to find reports about the rarity of eating disorders in non-Western societies, including Africa and Asia ${ }^{14,15}$. One of the arguments raised in support of this is that being overweight is not a common source of concern in most developing nations ${ }^{14}$. Studies however show considerable prevalence of disordered eating attitudes in both developed and developing countries including those in Africa ${ }^{16-19}$ the Middle East ${ }^{20,21}$, Europe and Asia ${ }^{22,23}$.

Earlier studies have established that the supposed rarity of eating disorders including disordered eating attitudes in non-Western climes has not been consistently so, with both intra-study and intra-country variations reported ${ }^{15,24}$. One study conducted in South Africa compared Black and Caucasian samples and reported concerns about body weight and shape among both Black and White populations $^{18}$. Findings from studies such as these have led to an increasing interest in the rates of disordered eating attitudes in the developing world by suggesting an increasing prevalence of disordered eating attitudes and eating disorders $^{25-27}$. It has been argued that communities that are considered as "Western" and in which eating disorders are more prevalent tend to influence non-Western societies in various ways including emphasis on thinness ${ }^{19,28}$. One of the ways by which this is possible is through the process of globalization which has encouraged the adoption of lifestyles from the more developed parts of the world including a desire to achieve the standards of beauty as defined by such societies ${ }^{29}$.

Earlier studies of disordered eating attitudes report varying rates including 10\% - 16\% from studies in the Americas $^{30,31}, 3 \%-13.7 \%$ in Europe ${ }^{22,32}, 4 \%-30 \%$ in Asia 3,20,23,33-35. Generally, studies of disordered eating attitudes among males reported rates ranging from $3 \%-4.5 \%{ }^{22,23}$. Further, in support of the prevalence of disordered eating attitudes, Szabo and Allwood reported a rate of $18.7 \%$ and $18.6 \%$ respectively within the Black and White sample of their South African study population ${ }^{18}$. In Nigeria, a survey of female Nigerian students reported a prevalence of $14.1 \%$ among high school, college and university students ${ }^{16}$.

Despite the severity and potential complications of dis- ordered eating attitudes, little is known about their prevalence and correlates in this environment. There is a need to undertake research in the area of eating disorders in this environment because very few studies, ${ }^{16-19}$ to the best of our knowledge, have examined the prevalence and correlates of disordered eating attitudes in Nigeria and West Africa. Additionally, this study has strength having included males, a group that is often neglected when eating disorders are studied. It is possible that findings from this study will shed more light on the hypothesis that disordered eating attitudes and perhaps eating disorders are uncommon in this part of the world. We therefore investigated the prevalence and correlates of abnormal eating attitudes among undergraduate students of public higher institutions in Lagos, Nigeria.

\section{Methodology}

This cross-sectional descriptive study was conducted among undergraduates of two federal public higher institutions in Lagos, Nigeria: a College of Technology and University. The Yaba College of Technology is a tertiary institution of learning that offers courses in arts, science and engineering. The University of Lagos on the other hand offers courses across 12 faculties including arts, sciences, administration, and medical sciences among oth$\mathrm{ers}^{35}$.

During the years 2013-2015, we administered a set of questionnaires to a sample of 1054 male and female undergraduates from two Nigerian institutions. The study participants were representative of Nigerian students particularly those in Southwestern Nigeria.The study participants were interviewed using a demographic questionnaire, the 12-item General Health Questionnaire (GHQ$12)^{36-39}$ and the 26-item Eating Attitudes Test(EAT-26) questionnaire $^{18,40}$.

The demographic questionnaire collected information on age, gender, study institution, level/year of study, current height, weight and blood pressure. The last three parameters were directly measured and the values were filled into the questionnaire by the interviewer/research assistants. Height was measured with no shoes and was recorded to the nearest meter and blood pressure was recorded to the nearest millimeters of mercury. Weight was measured with light clothing and no shoes and was recorded to the nearest 0.1 kilogram. Both height and weight were used 
to calculate body mass index (BMI). Each participant was asked to stand straight ahead unassisted in the center of the platform in which the scale was checked for zero balance before each measurement. In addition, the respondents were required to specify paternal occupation and employment status, which was for the purpose of establishing socio-economic status.

The GHQ-12 is a brief self-administered measure which has been used in various settings for screening psychological disorders. ${ }^{36-39}$ The GHQ-12 bimodal scoring (0-0-11) method was employed. The total GHQ-12 score was generated by combining all the items with participants' scores ranging from $0-12$, and score greater than 3 was categorized as indicative of "psychological distress". 36-39

The EAT-26 is a self-report questionnaire comprising questions dealing with attitudes, concerns and behaviors related to food, weight and body shape ${ }^{40}$. The EAT-26 was used as a screening measure for eating disorders. A score of 20 and above is considered suggestive of the existence of disturbed eating attitudes and behaviors. Based on the total score obtained on the EAT- 26 as well as a profile of the eating attitudes of the sub-scale scores obtained, the EAT-26 questionnaire provides information on the eating disorder behavior. The EAT-26, being a self-report questionnaire was self-administered with supervision by the researchers to ensure completeness. The term "binge" was defined to all the participants as majority of respondents were not familiar with it. The EAT-26 has been validated in a Nigerian population ${ }^{17}$. A Cronbach's alpha of 0.75 and 0.79 has previously been established among Black and White respondents in a South African study that employed the EAT-26 ${ }^{18}$. Our study was conducted in English, the official language of instruction in Nigeria.
Ethical approval for the study was sought and obtained from the two public higher institutions where the study was conducted. Participation in the study was voluntary, each participant was required to provide written informed consent, and anonymity was guaranteed. Study participants who complained to the investigators about physical symptoms were counselled and referred appropriately.

Data was analyzed using the $20^{\text {th }}$ version of the Statistical Package for Social Sciences (SPSS-20) for descriptive and analytical statistics. Mean and standard deviations were reported for the continuous variables, EAT-26 $6^{18,40}$ scores as well as for the sub-scale scores. Chi-square statistics was used to compare the rates of abnormal eating attitudes based on the different socio-demographic and clinical variables. The significant level adopted was set at 0.05 . In view of incomplete questionnaire leading to ignorable "missing completely at random" data, analyses of specific items were done using complete-case analyses method $^{41,42}$, and the frequency for complete data used in the analyses of specific items were shown in the results and tables.

\section{Results}

The study comprised 1,054 respondents in total from the two higher institutions of learning. Majority of the students approached to participate in the study gave their consent. Age was the least endorsed variable with about $92 \%$ response rate.

\section{Sociodemographic and clinico-anthropometric char- acteristics of participants}

As shown in table 1: five hundred and ten (48.4\%) respondents were students of the College of Technology while the remainder were students of theUniversity. The study sample was made up of 561 males accounting for $55.6 \%$ of the respondents. The median age was 21.4 years (range $16-44)$. Only $28(2.7 \%)$ of the study participants were married while $4.7 \%$ reported that their fathers were unemployed as at the time of data collection. 
Table 1 - Socio-demographic characteristics of respondents

\begin{tabular}{|c|c|c|}
\hline Variables & Frequency (n) & Percentage $(\%)$ \\
\hline \multicolumn{3}{|l|}{$\operatorname{Age}-y r s(n=970)$} \\
\hline$<20$ & 480 & 49.5 \\
\hline $21-30$ & 473 & 48.8 \\
\hline $31-40$ & 14 & 1.4 \\
\hline$>40$ & 3 & 0.3 \\
\hline \multicolumn{3}{|l|}{ Median age $=21.4$ years } \\
\hline \multicolumn{3}{|l|}{ Range $=16-44$ years } \\
\hline \multicolumn{3}{|l|}{ Gender $(n=1009)$} \\
\hline Male & 561 & 55.6 \\
\hline Female & 448 & 44.4 \\
\hline \multicolumn{3}{|l|}{ Marital status $(n=1046)$} \\
\hline Married & 28 & 2.7 \\
\hline Unmarried & 1018 & 97.3 \\
\hline \multicolumn{3}{|l|}{ Ethnicity $(n=1033)$} \\
\hline Yoruba & 710 & 68.7 \\
\hline Igbo & 189 & 18.3 \\
\hline Hausa & 6 & 0.6 \\
\hline Others & 128 & 12.4 \\
\hline \multicolumn{3}{|l|}{ Religion $(n=1053)$} \\
\hline Christianity & 859 & 81.6 \\
\hline Islam & 185 & 17.6 \\
\hline Others & 9 & 0.8 \\
\hline \multicolumn{3}{|l|}{ Institution $(n=1054)$} \\
\hline College of Technology & 510 & 48.4 \\
\hline University & 544 & 51.6 \\
\hline \multicolumn{3}{|c|}{ FathersEmployment status $(n=979)$} \\
\hline Employed & 933 & 95.3 \\
\hline Unemployed & 46 & 4.7 \\
\hline
\end{tabular}

Regarding the clinical and anthropometric parameters measured which are depicted in table 2, the average weight and height was 63.3 kilograms and 1.69 meters respectively. The mean $\mathrm{BMI}$ was $22.17 \mathrm{~kg} / \mathrm{m}^{2}(\mathrm{SD}=3.58)$. The mean BMI for males and female respondents was $21.94(\mathrm{SD}=3.81)$ and $22.14(\mathrm{SD}=4.07)$ respectively. The systolic blood pressure measured ranged from 90 to 196 $\mathrm{mmHg}$ with a mean of $123 \mathrm{mmHg}$, while the average diastolic blood pressure was $72.44 \mathrm{mmHg}$ (range 50 - 119).

\section{Prevalence of disordered eating attitude}

EAT-26 scores for all respondents ranged between 0 and 59, and following categorization, $169(16 \%)$ scored 20 or above and were thus categorized as having abnormal eating attitudes (table 2). The mean score for the entire sample $(\mathrm{n}=1054)$ was $11.52(\mathrm{SD}=8.54)$. The mean EAT26 score for males and females were $10.44(\mathrm{SD}=7.80)$ and $12.83(\mathrm{SD}=9.26)$ respectively. The mean $(\mathrm{SD})$ scores for the various sub-scales were as follow: dieting $=6.59$ (5.58), bulimic $=1.18$ (1.98), oral control $=3.75$ (3.61). For those scoring 20 or above $(n=169)$ on the EAT-26, the mean (SD) score was 26.39 (6.64) with the mean (SD) score for the subscales being as follows: dieting $=15.17$ (5.6), Bulimic $=3.14$ (3.11), oral control $=8.08$ (4.15). For respondents scoring below $20(\mathrm{n}=885)$ on the EAT26 , the mean (SD) score was 8.68 (5.30), while the mean (SD) scores for the various sub-scales were as follows: dieting $=4.96(3.80)$, bulimic $=0.80(1.40)$, oral control $=$ $2.92(2.83)$. 
Table 2: Clinical and anthropometric characteristics of respondents

\begin{tabular}{|c|c|c|}
\hline Variables & Frequency (n) & Percentage (\%) \\
\hline \multicolumn{3}{|l|}{$G H Q(n=1054)$} \\
\hline No distress & 711 & 67.5 \\
\hline Distress & 343 & 32.5 \\
\hline \multicolumn{3}{|l|}{$E A T-26(n=1054)$} \\
\hline Disordered Eating attitude & 169 & 16.03 \\
\hline No Disorder & 885 & 83.97 \\
\hline \multicolumn{3}{|l|}{ Weight - Kgs $(n=1036)$} \\
\hline Mean $( \pm \mathrm{SD})$ & $63.29( \pm 11.14)$ & \\
\hline \multicolumn{3}{|l|}{ Height - Metres $(n=1041)$} \\
\hline Mean $( \pm \mathrm{SD})$ & $1.69( \pm 0.8951)$ & \\
\hline \multicolumn{3}{|l|}{ BMI (n-1036) } \\
\hline Mean $( \pm$ SD) & $22.17( \pm 3.58)$ & \\
\hline \multicolumn{3}{|c|}{ Systolic BP $-\mathrm{mmHg}(n=1054)$} \\
\hline Mean $( \pm \mathrm{SD})$ & $123.0( \pm 12.27)$ & \\
\hline \multicolumn{3}{|c|}{ Diastolic BP mmHg $(n=1054)$} \\
\hline Mean $( \pm$ SD $)$ & $72.44( \pm 8.82)$ & \\
\hline
\end{tabular}

\section{Correlates of disordered eating attitude}

Table 3 shows the relationship between eating attitudes and sociodemographic characteristics of the respondents. There was an association between eating attitudes and age with respondents who were older being more likely to experience disordered eating attitudes $\left(X^{2}=9.208, \mathrm{df}=3\right.$, $\mathrm{p}=0.027)$. Additionally, there was an association between gender and disordered eating attitudes with females be- ing more likely to experience disordered eating attitudes $\left(\mathrm{X}^{2}=18.714, \mathrm{df}=1, \mathrm{p}=<0.001\right)$. A similar association was also found with respect to the institution of study with students of the College of Technology being more likely to report disordered eating attitudes $\left(\mathrm{X}^{2}=7.894, \mathrm{df}=1, \mathrm{p}=\right.$ 0.005). Our study found no association between eating attitudes and all other sociodemographic characteristics that were examined. 
Table 3: Socio-demographic correlates of abnormal eating attitudes

\begin{tabular}{|c|c|c|c|c|c|}
\hline Variables & Disorder & $\begin{array}{c}\text { No } \\
\text { Disorder }\end{array}$ & $x^{2}$ & df & $\mathbf{p}$ \\
\hline \multicolumn{6}{|l|}{ Age $-y r s(n=970)$} \\
\hline$<20$ & $72(15.0)$ & $408(85.0)$ & 9.208 & 3 & $\mathbf{0 . 0 2 7}$ \\
\hline $21-30$ & $81(17.1)$ & $392(82.9)$ & & & \\
\hline $31-40$ & 0 & $14(100.0)$ & & & \\
\hline$>40$ & $2(66.7)$ & $1(33.3)$ & & & \\
\hline \multicolumn{6}{|l|}{ Gender $(n=1009)$} \\
\hline Male & $65(11.6)$ & $496(88.4)$ & $18.714^{\#}$ & 1 & $<\mathbf{0 . 0 0 1}$ \\
\hline Female & $98(21.9)$ & $350(78.1)$ & & & \\
\hline \multicolumn{6}{|l|}{ Marital Status $(n=1046)$} \\
\hline Married & $7(25.0)$ & $21(75.0)$ & $1.127^{\#}$ & 1 & 0.288 \\
\hline Married & $160(15.7)$ & $858(84.3)$ & & & \\
\hline \multicolumn{6}{|l|}{ Ethnicity $(n=1033)$} \\
\hline Yoruba & $116(16.3)$ & $594(83.7)$ & 1.219 & 3 & 0.748 \\
\hline Igbo & $32(16.9)$ & $157(83.1)$ & & & \\
\hline Hausa & $0(0.0)$ & $6(100.0)$ & & & \\
\hline Others & $21(16.4)$ & $107(83.6)$ & & & \\
\hline \multicolumn{6}{|l|}{ Religion $(n=1053)$} \\
\hline Christianity & $140(16.3)$ & $719(83.7)$ & 2.582 & 2 & 0.275 \\
\hline Islam & $26(14.1)$ & $159(85.9)$ & & & \\
\hline Others & $3(33.3)$ & $6(66.7)$ & & & \\
\hline \multicolumn{6}{|l|}{ Institution $(n=1054)$} \\
\hline College of Technology & $99(19.4)$ & $411(80.6)$ & $7.894^{\#}$ & 1 & $\mathbf{0 . 0 0 5}$ \\
\hline University & $70(12.9)$ & $474(87.1)$ & & & \\
\hline \multicolumn{6}{|c|}{ Fathers employment status $(n=979)$} \\
\hline Employed & $154(16.5)$ & $779(83.5)$ & $0.651^{\#}$ & 1 & 0.420 \\
\hline Unemployed & $5(10.9)$ & $41(89.1)$ & & & \\
\hline
\end{tabular}

Table 4 shows the relationship between respondents' clinico-anthropometric characteristics and disordered eating attitudes. There was a statistically significant difference in both the height and systolic blood pressure with respondents who reported disordered eating attitudes being more likely to be shorter $(\mathrm{t}=-2.402, \mathrm{df}=1039$, $\mathrm{p}=0.016$ )and to record a lower systolic blood pressure $(t=-2.353, d f=1052, p=0.019)$. Further, respondents who reported disordered eating attitudes were significantly more likely to be psychologically distressed $\left(\mathrm{X}^{2}=7.715\right.$, $\mathrm{df}=1, \mathrm{p}=0.005)$ and to have a higher BMI $\left(\mathrm{X}^{2}=2.209\right.$, $\mathrm{df}=1, \mathrm{p}=0.027)$. 
Table 4: Clinical and anthropometric correlates of abnormal eating attitudes

\begin{tabular}{|c|c|c|c|c|c|}
\hline Variables & $\begin{array}{l}\text { Disorder } \\
\text { n/Mean }( \pm \text { SD) }\end{array}$ & $\begin{array}{l}\text { No Disorder } \\
\text { n/Mean }( \pm \text { SD) }\end{array}$ & $\mathbf{t}$ & df & $\mathbf{p}$ \\
\hline Weight $-k g(n=1036)$ & $\begin{array}{l}166 \\
63.12( \pm 11.60)\end{array}$ & $\begin{array}{l}870 \\
63.32( \pm 11.06)\end{array}$ & -0.211 & 1034 & 0.833 \\
\hline Height - Metres $(n=1041)$ & $\begin{array}{l}165 \\
1.67( \pm 0.09)\end{array}$ & $\begin{array}{l}876 \\
1.69( \pm 0.09)\end{array}$ & -2.402 & 1039 & 0.016 \\
\hline Systolic BP $-m m H g(n=1054)$ & $\begin{array}{l}169 \\
120.95( \pm 11.02)\end{array}$ & $\begin{array}{l}885 \\
123.38( \pm 12.47)\end{array}$ & -2.353 & 1052 & 0.019 \\
\hline Diastolic BP $-m m H g \quad(n=1054)$ & $\begin{array}{l}169 \\
72.33( \pm 8.84)\end{array}$ & $\begin{array}{l}885 \\
72.46( \pm 8.83)\end{array}$ & -0.169 & 1052 & 0.866 \\
\hline $\begin{array}{l}G H Q(n=1054) \\
\text { No distress } \\
\text { Distress }\end{array}$ & $\begin{array}{l}98(13.8) \\
71(20.7)\end{array}$ & $\begin{array}{l}613(86.2) \\
272(79.3)\end{array}$ & $7.715^{\#}$ & 1 & 0.005 \\
\hline$B M I(n=1036)$ & $\begin{array}{l}166 \\
22.73( \pm 4.94)\end{array}$ & $\begin{array}{l}870 \\
22.06( \pm 3.24)\end{array}$ & 2.209 & 1034 & 0.027 \\
\hline
\end{tabular}

${ }^{\beta}=$ Chi-square; ${ }^{\#}=$ Yate's correction; $\mathrm{kg}=$ Kilograms; $B P=$ Blood Pressure; $G H Q=$ General Health Questionnaire; $B M I$ $=$ Body Mass Index; $m m H g=$ millimeters of Mercury; $t=t$-test $; d f=$ degree of freedom; bold $=p$-value significant at $<0.05$

\section{Discussion}

The periods of adolescence and young adulthood are ones that may be particularly characterized by concerns about body image compared to other stages of human development. This study revealed that abnormal eating attitudes are prevalent among young people in our environment. We found that $16.0 \%$ of Nigerian adolescents and young people in two public tertiary institutions had abnormal eating attitudes. The findings of this study can be compared with similar studies of disordered eating attitude in sub-Saharan Africa and Nigeria ${ }^{17,18}$ which reported similar rates of disordered eating attitudes. Some other studies, mainly from South Africa reported lower disordered eating attitude rates such as one by Szabo and Allwood who reported a rate of $3 \% 0^{43}$. This study was however conducted among rural Zulu speaking females with the rates being also lower than that obtained in a similar study by the same authors ${ }^{18}$, suggesting that cultural as well as feeding practices which differ between rural and urban settings may contribute to the prevalence of disordered eating attitudes. Indeed another study conducted in urban South Africa found lower rates of disordered eating attitude of $3.5 \%$ with the authors concluding that "ethnicity per se may not 'protect' against the development of disordered eating attitudes and behaviors in non-Western Black populations" 24 . Our study can also be compared with similar studies conducted in Iran, Brazil and Canada where prevalence rates of $24.2 \%, 13.4 \%$, and $8.4 \%$ respectively have been reported ${ }^{3,31,44}$. The Canadian sample however comprised of people between 18 and 98 years of age. Additionally, as is expected and previously reported in diverse studies from all over the world, this study found a higher prevalence of disordered eating attitudes in young females $(21.9 \%)$ compared to males $(11.6 \%)$. This finding suggests that females may be more concerned about body size ideals and body image. They may therefore engage in abnormal eating attitudes as a means to achieving what they consider the ideal body shape or size.

In a previous study in this environment, the reported prevalence rate of abnormal eating attitudes was $14.1 \%{ }^{17}$, which is similar to that from our study. However, considering that the study was conducted solely among females, the findings from our study suggests an increase in the prevalence of disordered eating attitudes within the past two decades. This finding may be attributed to increasing awareness among young people about their physical appearance, increased exposure of young peo- 
ple to western lifestyles including fashion among others. Additionally, the act of body shaming is also increasingly being observed as well, especially on social media ${ }^{45}$. A good example is the increasing availability and exposure to digital/cable television compared to the period when the previous study was conducted. It is also possible that the age range of the participants from the previous study may have influenced the findings, as the study included high school students who were younger than most of our study participants.

The findings from this study showed age, gender, institution, height, systolic blood pressure, and BMI as correlates of abnormal eating attitudes. These findings are similar in some regard to those reported in previous studies examining the correlates of eating disorders or abnormal eating attitudes including gender, age, ,3,21,46 $^{\text {, body }}$ weight ${ }^{24,46}$, and $\mathrm{BMI}^{3,21,24,46}$.

Our study showed that respondents who are older are more likely to experience abnormal eating attitudes. While this finding may be biased due to the relatively small sample size of respondents who are older than 30 years compared to the other age groups, a possible reason for this finding is the desire for the older students to fit in among their colleagues considering that the desire to identify with a peer group is one of a common defining feature of undergraduate students. With regards to gender, the finding that females were more likely to have disordered eating attitude was not surprising as it has been documented in literature that females are more likely to have concerns about their appearance and looks ${ }^{32,33,35,43,47}$. Likewise studies have largely reported the preponderance of body-image disorders and eating disorders among females $^{3,32,35,43}$, to the extent that majority of studies reviewed were conducted solely among females. $7,16,19,26,30,33,34$

The participants who were students of the College of Technology tend to have disordered eating attitudes compared to those sampled from the University. In Nigeria, there appears to be some discrimination against undergraduates and graduates of College of Technology in favour of their University counterparts ${ }^{48}$, which may impact negatively on the self-esteem of students in College of Technology. The findings from our work may therefore be a reflection of what students in College of Technology consider to be "ideal" in a bid to measure up to certain standards.

African Health Sciences Vol 17 Issue 2, June, 2017
Generally, we noted that respondents who were shorter were more likely to have disordered eating attitudes. The reasons for this finding may not be unrelated to the same reasons why individuals with a higher BMI are more likely to experience disordered eating attitudes. This is particularly because it has been argued that persons who are short are more likely to record a higher BMI compared to those who are taller assuming they have similar weights ${ }^{49}$. By extension, participants in our study who had a higher BMI were more likely to have disordered eating attitudes and this is unsurprising. These individuals may be uncomfortable with their seemingly "unacceptable" weight in relation to their height and therefore engage in unhealthy eating attitudes as a way of dealing with their appearance. The association between disordered eating attitudes and psychological distress as seen in this study is likely an indication of distressing nature/impact of dissatisfaction with an individuals' body image on their mental health. It is also possible that participants may engage in abnormal eating attitudes as a way of coping with pre-existing psychological distress.

\section{Limitations}

One limitation of this study is the fact that we employed the use of self-report questionnaires as participants may have chosen to give socially desirable responses to some of the items on the questionnaires. Another limitation of our study is the use of a non-probability method of sampling which may have introduced some bias in the selection of study participants. Additionally, this study examined the rates of disordered eating attitudes among students of only two of the several higher institutions of the country and in only one of the 36 states. The finding from the study may therefore not be representative of young people in general. As previously suggested in other cultures $^{29}$, the EAT-26 used in this study may be culturally biased and may therefore not be a reliable instrument in screening for eating disorders in this environment ${ }^{29}$. We noted earlier that age had the least response rate in this study, and the varied response rates amongst all the variables in this study may have resulted in some non-response bias.

This study however has strength in being one of the few studies in the last two decades to have been conducted in this environment to our knowledge. Further, this study examined the prevalence and correlates of abnormal eating attitudes among both male and female undergraduates. It is one of the few studies that have specifically examined male subjects. 


\section{Conclusion}

The findings from this study on abnormal eating attitudes suggest a need to incorporate awareness program about nutrition into school curriculum as a means to preventing increased prevalence of disordered eating attitudes. Other forms of training may include those that concern the health problems associated with un-prescribed dietary restriction hazards, weight loss methods and symptoms of eating disorders. There is also a need for parents, counsellors, teachers, peer educators and others to be involved in assisting young people to build their self-esteem as a means of being confident and happy with their body ${ }^{3}$.

The high prevalence of abnormal eating attitudes in our study suggests a need for further research to determine the prevalence of eating disorders, and perhaps examine culture specific criteria for eating disorders in this environment. There may also be need to examine the prevalence pattern among populations such as models and entertainers who are reputed to pay attention and value to beauty as well as physical appearance. Overall, large scale population studies using validated diagnostic tools are needed in this environment to determine accurate prevalence rates of eating disorders.

\section{Acknowledgements}

We acknowledge the University of Lagos and the Tertiary Education Trust Fund for a grant (CRC/TETFUND/ NO.2011/15) towards carrying out this research work.

\section{Conflict of interest}

We have no new conflict of interest to declare.

\section{References}

1. Herpertz-Dahlmann B, Wille N, Hölling H, Vloet TD, Ravens-Sieberer U. Disordered eating behaviour and attitudes, associated psychopathology and health-related quality of life: results of the BELLA study. Eur Child Adolesc Psychiatry. 2008 Dec;17 Suppl 1:82-91.

2. Mousa TY, Mashal RH, Al-Domi HA, Jibril MA. Body image dissatisfaction among adolescent schoolgirls in Jordan. Body Image. 2010 Jan;7(1):46-50.

3. Rauof M, Ebrahimi H, Asghari Jafarabadi M, Malek A, Babapour Kheiroddin J. Prevalence of Eating Disorders Among Adolescents in the Northwest of Iran. Iran Red Crescent Med J. 2015 Oct;17(10):e19331.

4. World Health Organisation. International Classifica- tion of Diseases (ICD). $10^{\text {th }}$ Editi. Geneva: World Health Organization; 2008.

5. American Psychiatric Association. Diagnostic and statistical manual of mental disorders. 5th Ed. Arlington, VA: American Psychiatric Publishing, 2013.

6. Chamay-Weber C, Narring F, Michaud PA. Partial eating disorders among adolescents: a review. J Adolesc Heal. 2005;37 (5):417-27. PubMed

7. Pourghassem Gargari B, Kooshavar D, Seyed Sajadi N, Safoura S, Hamed Behzad M, Shahrokhi H. Disordered Eating Attitudes and Their Correlates among Iranian High School Girls. Heal Promot Perspect. 2011;1(1):41-9. PubMed

8. Dos Santo Alvarenga M, Scagliusi FB, Philippi ST. Development and validity of the Disordered Eating Attitude Scale (DEAS). Percept Mot Skills. 2010;110(2):379-95.

9. Visser J, Notelovitz T, Szabo C, Fredericks N. Abnormal eating attitudes and weight-loss behaviour of adolescent girls attending a "traditional" Jewish high school in Johannesburg, South Africa. South African J Clin Nutr. 2014;27(4):208-16.

10. Graber JA, Tyrka AR, Brooks-Gunn J. How similar are correlates of different subclinical eating problems and bulimia nervosa? J Child Psychol Psychiatry. 2003 Feb;44(2):262-73.

11. Papadopoulos FC, Ekbom A, Brandt L, Ekselius L. Excess mortality, causes of death and prognostic factors in anorexia nervosa. Br J Psychiatry. 2009 Jan;194(1):10-7. 12. Swanson SA, Crow SJ, Le Grange D, Swendsen J, Merikangas KR. Prevalence and correlates of eating disorders in adolescents. Results from the national comorbidity survey replication adolescent supplement. Arch Gen Psychiatry. American Medical Association; 2011 Jul 4;68(7):714-23. 13. Jenkins PE, Hoste RR, Doyle AC, Eddy K, Crosby RD, Hill L, et al. Health-related quality of life among adolescents with eating disorders. J Psychosom Res. 2014 Jan;76(1):1-5.

14. Shuriquie N. Eating disorders: a transcultural perspective. East Mediterr Heal J. 1999;5(2):354-60.

15. Soh N., Touyz S., Surgenor L. Eating and Body Image Disturbances Across Cultures: A Review. Eur Eat Disord Rev. 2006;14:54- ;65. PubMed

16. Oyewumi LK, Kazarian SS. Abnormal eating attitudes among a group of Nigerian youths: I. Bulimic behaviour. East Afr Med J. 1992 Dec;69(12):663-6.

17. Oyewumi LK, Kazarian SS. Abnormal eating attitudes among a group of Nigerian youths: II. Anorexic behaviour. East Afr Med J. 1992 Dec;69(12):667-9. 
18. Szabo CP, Allwood CW. A cross-cultural study of eating attitudes in adolescent South African females. World Psychiatry. World Psychiatric Association; 2004 Feb;3(1):414.

19. Dike I. Anorexia and bulimia nervosa: The scenario among Nigerian female students. Int J Guid Couns. 2014;2(3):17-20. PubMed

20. al-Subaie A, al-Shammari S, Bamgboye E, al-Sabhan K, al-Shehri S, Bannah AR. Validity of the Arabic version of the Eating Attitude Test. Int J Eat Disord. 1996 Nov;20(3):321-4.

21. Eapen V, Mabrouk AA, Bin-Othman S. Disordered eating attitudes and symptomatology among adolescent girls in the United Arab Emirates. Eat Behav. 2006 Jan;7(1):53-60.

22. Saporetti G, Sancini S, Bassoli L, Castelli B, Pellai A. [Risk assessment for eating disorders in a high school: a study based on the Eating Attitudes Test 26]. Minerva Pediatr. 2004 Feb;56(1):83-90.

23. Yu J, Lu M, Tian L, Lu W, Meng F, Chen C, et al. Prevalence of Disordered Eating Attitudes among University Students in Wuhu, China. Nutr Hosp. 2015;32(4):1752-7. 24. le Grange D, Louw J, Russell B, Nel T, Silkstone C. Eating attitudes and behaviours in South african adolescents and young adults. Transcult Psychiatry. 2006 Sep;43(3):401-17.

25. Le Grange D, Telch CF, Tibbs J. Eating Attitudes and Behaviors in 1,435 South African Caucasian and Non-Caucasian College Students. Am J Psychiatry. 1998;155:250-254

26. Wassenaar D, le Grange D, Winship J, Lachenicht L. The prevalence of eating disorder pathology in a cross-ethnic population of female students in South Africa. Eur Eat Disord Rev. 2000 May;8(3):225-36.

27. Pike KM, Hoek HW, Dunne PE. Cultural trends and eating disorders. Curr Opin Psychiatry. 2014 Nov;27(6):43642.

28. Mchiza Z. Eating disorders in South African schools: a public health crisis that needs immediate intervention. South African Journal of Clinical Nutrition. 2014 27(4):1-2.

29. Makino M, Tsuboi K, Dennerstein L. Prevalence of eating disorders: a comparison of Western and non-Western countries. Med Gen Med. 2004 Jan;6(3):49.

30. Jones JM, Bennett S, Olmsted MP, Lawson ML, Rodin G. Disordered eating attitudes and behaviours in teenaged girls: a school-based study. CMAJ. 2001 Sep 4;165(5):547-52.
31. Vilela JEM, Lamounier JA, Dellaretti Filho MAD, Barros Neto JR, Horta GM. Eating disorders in school children. J Pediatr (Rio J). 2004;80(1):49-54.

32. Solmi F, Hatch SL, Hotopf M, Treasure J, Micali N. Prevalence and correlates of disordered eating in a general population sample: the South East London Community Health (SELCoH) study. Soc Psychiatry Psychiatr Epidemiol. 2014 Aug;49(8):1335-46.

33. Lee AM, Lee S. Disordered eating and its psychosocial correlates among Chinese adolescent females in Hong Kong. Int J Eat Disord. 1996 Sep;20(2):177-83.

34. Latzer Y, Azaiza F, Tzischinsky O. Not just a western girls' problem: eating attitudes among Israeli-Arab adolescent boys and girls. Int J Adolesc Youth. 2014;19(3):382-94. 35. Aina OF, Olagunju AT, Akinbode AA, Suleiman TF. Screening for eating disorders among undergraduate students in two Nigerian institutions. Unilag Journal of Medicine, Science and Technology. 2016; 4:1 pg 148-158

36. Goldberg D, Gater R, Sartorius N, Ustun T, Piccinelli M, Gureje $\mathrm{O}$, et al. The validity of two versions of the GHQ in the WHO study of mental illness in general health care. Psychological Med. 1997;27(1):191-7.

37. Ogundipe OA, Olagunju AT, Lasebikan VO, Coker AO. Burnout among doctors in residency training in a tertiary hospital. Asian J Psychiatr. 2014;10:27-32.

38. Olagunju AT, Adeyemi JD, Erinfolami AR, Aina OF. HIV/AIDS and Psychological distress: the experience of outpatients in a West African HIV clinic. HIV/AIDS Rev. 2012;11:31-5.

39. Gureje O, Obikoya B. The GHQ-12 as a screening tool in a primary care setting. Soc Psychiatry Psychiatr Epidemiol. 1990;25(5):276-80.

40. Garner DM, Olmsted MP, Bohr Y, Garfinkel PE The The Eating Attitudes Test: psychometric features and clinical correlates. Psychol Med. 1982;12:871-878.

41. Pigott TD. A Review of Methods for Missing Data. Educational Research and Evaluation. 2001; 7(4):353-383 42. Rubin DB. Inference and missing data. Biometrika. 1976;63:581-592 PubMed .

43. Szabo CP, Allwood CW. Application of the Eating Attitudes Test (EAT-26) in a rural, Zulu speaking, adolescent population in South Africa. World Psychiatry. 2004 Oct;3(3):169-71.

44. Johnson CS, Bedford J. Eating attitudes across age and gender groups: a Canadian study. Eat Weight Disord. 2004 Mar;9(1):16-23.

45. Andrew R, Tiggemann M, Clark L. The protective 
role of body appreciation against media-induced body dissatisfaction. Body Image. 2015;15:98-;104. PubMed 46. Wong Y, Lin J-S, Chang Y-J. Body satisfaction, emotional intelligence, and the development of disturbed eating: a survey of Taiwanese students. Asia Pac J Clin Nutr. 2014 Jan;23(4):651-9.

47. Granillo T, Jones-Rodriguez G, Carvajal SC. Prevalence of eating disorders in Latina adolescents: Associ- ations with substance use and other correlates. $J$ Adolesc Heal. 2005;36(3):214 -20. PubMed

48. Asibeluo IS. The Effects of the Discrimination between Polytechnic Education and University Education on the Overall Technological Development of Nigeria. Ind Eng Lett. 2015;5(4):41-6. PubMed

49. Cohen DA, Sturm R. Body mass index is increasing faster among taller persons. Am J Clin Nutr. 2008 Feb 1;87(2):445-8. 